\title{
MicroRNA-503 serves an oncogenic role in laryngeal squamous cell carcinoma via targeting programmed cell death protein 4
}

\author{
YU SHUANG ${ }^{1,2^{*}}$, XUAN ZHOU $^{1 *}, \mathrm{CHAO} \mathrm{LI}^{2}$, YONGWANG HUANG $^{2}$ and LUN ZHANG ${ }^{1}$ \\ ${ }^{1}$ Department of Otorhinolaryngology and Maxillofacial Oncology, Tianjin Medical University Cancer \\ Institute and Hospital, Key Laboratory of Cancer Prevention and Therapy, Tianjin Cancer Institute, National \\ Clinical Research Center of Cancer, Tianjin 300060; ${ }^{2}$ Department of Otorhinolaryngology, Head and \\ Neck Surgery, The Second Hospital of Tianjin Medical University, Tianjin 300211, P.R. China
}

Received September 21, 2016; Accepted June 22, 2017

DOI: $10.3892 / \mathrm{mmr} .2017 .7278$

\begin{abstract}
Laryngeal squamous cell carcinoma (LSCC), the most common form of laryngeal carcinoma, is an aggressive malignancy that demonstrates the second highest rate of morbidity of all head and neck squamous cell carcinomas. The abnormal expression of microRNAs (miRs) has been demonstrated in a number of types of human cancer, and they have been demonstrated to be oncogenes or tumour suppressor genes. miR-503 has been studied in various types of human cancer; however, the expression level, roles and underlying mechanisms in LSCC remain unknown. In the present study, it was demonstrated that miR-503 was significantly upregulated in LSCC tissues and cell lines. The level of miR-503 in LSCC tissues was correlated with thyroid cartilage invasion, lymph node metastasis, and tumour, node and metastasis stage. In addition, down-regulation of miR-503 inhibited cell proliferation and invasion in LSCC. Programmed cell death protein 4 (PDCD4) was identified to be a direct target gene of miR-503. PDCD4 overexpression could mimic the roles of miR-503 underexpression in LSCC. Furthermore, PDCD4 was down-regulated in LSCC tissues and this correlated with the miR-503 expression level. In conclusion, these results suggested that miR-503 promotes tumour growth and invasion by directly targeting PDCD4. The identification of the miR-503/PDCD4 axis may provide novel targets for LSCC treatment and improve prognosis.
\end{abstract}

Correspondence to: Professor Lun Zhang, Department of Otorhinolaryngology and Maxillofacial Oncology, Tianjin Medical University Cancer Institute and Hospital, Key Laboratory of Cancer Prevention and Therapy, Tianjin Cancer Institute, National Clinical Research Center of Cancer, 1 Huanhu West Road, Tianjin 300060, P.R. China

E-mail: zhanglun_tijmu@163.com

${ }^{*}$ Contributed equally

Key words: laryngeal squamous cell carcinoma, programmed cell death protein 4 , microRNA-503, prognosis, therapy

\section{Introduction}

Head and neck cell carcinoma represents the seventh most common type of cancer in the world, which is comprised of oral cavity, oropharyngeal, hypopharyngeal and laryngeal carcinomas $(1,2)$. Laryngeal squamous cell carcinoma (LSCC), the most common form of laryngeal carcinoma, accounts for $\sim 25 \%$ of all head and neck squamous cell carcinomas (3). LSCC is an aggressive malignancy that has the second highest rate of morbidity of all head and neck squamous cell carcinomas, particularly in the northern area of China (4). Currently, the aetiology of LSCC remains poorly understood. It is hypothesised that smoking, drinking alcohol, exposure to harmful dust and human papilloma virus infection is involved in the initiation and progression of LSCC (5). Despite the development of therapeutic treatments for LSCC, including surgery, chemotherapy and radiotherapy, the 5 -year overall survival rate of patients with this disease has not significantly improved over the past 10 years (6).

Therefore, a complete understanding of the mechanisms underlying carcinogenesis and progression in LSCC may provide novel therapeutic strategies to improve the prognosis of patients with LSCC.

MicroRNAs (miRs) are a group of endogenous, short and noncoding RNAs that negatively regulate gene expression through base pairing with the 3 '-untranslated regions (3'UTRs) of their target genes forming a stable duplex through Watson-Crick complementarities $(7,8)$. By recruiting and incorporating with the RNA-induced silencing complex, translation of the target mRNA transcript is inhibited and/or the mRNA is subject to degradation $(9,10)$. Thus far, $>900$ mature miRs have been identified in the human genome and may modulate the expression level of $>30 \%$ protein-coding genes in humans (11). Numerous studies have demonstrated that miR serves a significant role in diverse biological processes, including cell proliferation, cell cycle progression, apoptosis, survival, motility, invasion, metastasis, angiogenesis and morphogenesis (12-14). In addition, the abnormal expression of miRs has been demonstrated in a number of types of human cancer, as they have been demonstrated to be oncogenes or tumour suppressor genes $(15,16)$. These results suggested that miRs may be novel therapeutic targets for cancer therapy. 
miR-503 has been studied in various types of human cancer (17-20); however, the expression level, role and underlying mechanism in LSCC remains unknown. The purpose of the present study is to investigate the expression level and biological roles of miR-503 in regulation of LSCC cell proliferation and invasion. Another aim is to investigate the underlying mechanism of miR-503 in LSCC.

\section{Materials and methods}

Tissue samples. The present study was approved by the Ethics Committee of Tianjin Medical University Cancer Institute and Hospital (Tianjin, China). Informed consent was also obtained from all patients with LSCC prior to tissue sample collection. LSCC tissues and adjacent normal tissues were obtained from 48 patients who were treated with total or partial laryngectomy at Tianjin Medical University Cancer Institute and Hospital between February 2012 and November 2014. The age and sex distribution of patients involved in the present study is illustrated in Table I. None of these patients received chemotherapy or radiotherapy prior to surgery. All tissues were immediately frozen in liquid nitrogen and then stored at $-80^{\circ} \mathrm{C}$.

Cell lines and culture condition. LSCC (AMC-HN-8 and Tu-177), normal human keratinocyte ( $\mathrm{HaCaT})$ and human embryonic kidney (HEK293T) cell lines were purchased from the American Type Culture Collection (Manassas, VA, USA). Cells were cultured in Dulbecco's modified Eagle's medium (DMEM; Gibco; Thermo Fisher Scientific, Inc., Waltham, MA, USA) supplemented with $10 \%$ foetal bovine serum (FBS; Gibco; Thermo Fisher Scientific, Inc.) and antibiotics (100 U/ml penicillin and $100 \mathrm{mg} / \mathrm{ml}$ streptomycin) at $37^{\circ} \mathrm{C}$ in a humidified atmosphere with $5 \% \mathrm{CO}_{2}$.

Transient transfection. Cells were seeded into 6-well plates at a density of $60-70 \%$ confluence in DMEM containing $10 \%$ FBS without antibiotics at $37^{\circ} \mathrm{C}$. Following overnight incubation, cells were transfected with an miR-503 inhibitor (100 pmol), an miR inhibitor negative control (NC) inhibitor (100 pmol), pcDNA3.1-programmed cell death protein 4 (PDCD4; 2,500 ng) or pcDNA3.1 (all Chinese Academy of Sciences, Changchun, Jilin, China) using the Lipofectamine ${ }^{\circledR}$ 2000 reagent (Invitrogen; Thermo Fisher Scientific, Inc.). The miR-503 inhibitor sequence was 5'-CUGCAGAAC UGUUCCCGCUGCUA-3' and the NC inhibitor sequence was 5'-ACUACUGAGUGACAGUAGA-3'. Following 6-8 h incubation, the medium was replaced with a culture medium containing 10\% FBS. The Cell Counting kit-8 (CCK8) assay, reverse transcription-quantitative polymerase chain reaction (RT-qPCR), Transwell invasion assay and western blot analysis were performed at $24,48,48$ and $72 \mathrm{~h}$ post-transfection, respectively.

$R T-q P C R$. Total RNA was extracted using TRIzol ${ }^{\circledR}$ reagent (Invitrogen; Thermo Fisher Scientific, Inc.) from cells and tissues. The total concentration of RNA was detected using an ND-2000 spectrophotometer (NanoDrop Technologies; Thermo Fisher Scientific, Inc., Wilmington, DE, USA), according to the manufacturer's protocol. The relative expression of miR-503 was determined using the One Step SYBR $^{\circledR}$ PrimeScript $^{\mathrm{TM}}$ miRNA RT-PCR kit (Takara Bio, Inc., Otsu, Japan). The thermocycling conditions for qPCR were as follows: $42^{\circ} \mathrm{C}$ for $5 \mathrm{~min}, 95^{\circ} \mathrm{C}$ for $10 \mathrm{sec}$, followed by 40 cycles of $95^{\circ} \mathrm{C}$ for $5 \mathrm{sec}, 55^{\circ} \mathrm{C}$ for $30 \mathrm{sec}$ and $72^{\circ} \mathrm{C}$ for $30 \mathrm{sec}$. For PDCD4 mRNA expression, reverse transcription was performed using the Moloney murine leukaemia virus reverse transcriptase (M-MLV RT; Promega Corporation, Madison, WI, USA). The temperature protocol for reverse transcription was as follows: $95^{\circ} \mathrm{C}$ for $2 \mathrm{~min}$, followed by 20 cycles of $94^{\circ} \mathrm{C}$ for $1 \mathrm{~min}, 55^{\circ} \mathrm{C}$ for $1 \mathrm{~min}$ and $72^{\circ} \mathrm{C}$ for $2 \mathrm{~min}$, then a final extension at $72^{\circ} \mathrm{C}$ for $5 \mathrm{~min}$. This reaction included $1 \mu$ l Oligo (dT)12-18 $(500 \mu \mathrm{g} / \mathrm{ml}), 2 \mu \mathrm{l}$ total RNA, $1 \mu 110 \mathrm{mM}$ dNTP Mix, $4 \mu \mathrm{l}$ 5X First-Strand Buffer, $2 \mu 1$ 0.1 M DTT, $1 \mu 1$ RNaseOUT $^{\mathrm{TM}}$ Recombinant Ribonuclease Inhibitor (40 units $/ \mu 1$ ), $1 \mu \mathrm{l}$ (200 units) of M-MLV RT and $7 \mu \mathrm{l}$ distilled water. Relative expressions of PDCD4 mRNA were measured using SYBR Premix Ex Taq ${ }^{\mathrm{TM}}$ kits (Takara Bio Inc.). Amplification was performed with the following thermocycling conditions: $5 \mathrm{~min}$ at $95^{\circ} \mathrm{C}$, followed by 40 cycles of $95^{\circ} \mathrm{C}$ for $30 \mathrm{sec}$ and $65^{\circ} \mathrm{C}$ for $45 \mathrm{sec}$. The expressions of miR-503 and PDCD4 mRNA were normalised against the relative expression of RNU6-1 and GAPDH, respectively. The primers were designed as follows: miR-503, 5'-GCGTAGCAG CGGGAACAGT-3' (forward) and 5'-CCAGTGCGTGTCGTG GAGT-3' (reverse); U6, 5'-GCTTCGGCAGCACATATACTA AAAT-3' (forward) and 5'-CGCTTCACGAATTTGCGTGTC AT-3' (reverse); PDCD4, 5'-AAAGGCGACTAAGGAAAA ACTCATC-3' (forward) and 5'-GCCTATCCAGCAACCTTC CCT-3' (reverse); and GAPDH, 5'-AGTGCCAGCCTCGTC TCATAG-3' (forward) and 5'-CGTTGAACTTGCCGTGGG TAG-3' (reverse). Relative expression levels were calculated according to the $2^{-\Delta \Delta C q}$ method (21).

CCK8 assay. Transfected cells were collected and re-seeded into 96-well plates $\left(1 \times 10^{3}\right.$ cells/well). The CCK8 (Dojindo Molecular Technologies, Inc., Kumamoto, Japan) assay was performed at various time points $(24,36,48$ and $72 \mathrm{~h})$. In total, $10 \mu \mathrm{l}$ CCK8 solution was added to each well and incubated at $37^{\circ} \mathrm{C}$ for an additional $4 \mathrm{~h}$. The absorbance values at $450 \mathrm{~nm}$ were detected using a microplate reader (Bio-Rad Laboratories, Inc., Hercules, CA, USA).

Transwell ${ }^{\circledR}$ invasion assay. The invasion assay was performed using Transwell chambers (8- $\mu \mathrm{m}$ pore size; BD Biosciences, Franklin Lakes, NJ, USA) pre-coated with a Matrigel ${ }^{\circledR}$ matrix (BD Biosciences). Transfected cells were harvested at $48 \mathrm{~h}$ post transfection. The upper chamber was seeded with $5 \times 10^{4}$ cells in $300 \mu \mathrm{l} \mathrm{FBS-free} \mathrm{culture} \mathrm{medium.} \mathrm{Then} 500 \mu \mathrm{l}$ culture medium containing $20 \%$ FBS was added into the lower chamber. Following $48 \mathrm{~h}$ incubation at $37^{\circ} \mathrm{C}$, cells remaining on the top of the chamber were wiped away with cotton wool. The invading cells were fixed in $4 \%$ paraformaldehyde for $20 \mathrm{~min}$ at room temperature, stained with $0.5 \%$ crystal violet for $10 \mathrm{~min}$ at room temperature, washed with PBS and counted under an inverted microscope (5 fields/chamber). Each assay was repeated in three independent experiments.

Bioinformatic analysis. The potential target genes of miR-503 were analysed using the algorithms from TargetScan 
Table I. Association between miR-503 expression level and clinicopathological features of laryngeal squamous cell carcinoma.

\begin{tabular}{|c|c|c|c|c|}
\hline \multirow[b]{2}{*}{ Clinical features } & \multirow[b]{2}{*}{ Cases } & \multicolumn{2}{|c|}{$\begin{array}{c}\text { miR-503 } \\
\text { expression } \\
\text { level }\end{array}$} & \multirow[b]{2}{*}{ P-value } \\
\hline & & High & Low & \\
\hline Age, years & & & & 0.776 \\
\hline$<60$ & 22 & 13 & 9 & \\
\hline$\geq 60$ & 26 & 14 & 12 & \\
\hline Sex distribution & & & & 0.560 \\
\hline Male & 20 & 10 & 10 & \\
\hline Female & 28 & 17 & 11 & \\
\hline Primary location & & & & 0.383 \\
\hline Supraglottic & 23 & 11 & 12 & \\
\hline Glottic & 25 & 16 & 9 & \\
\hline Thyroid cartilage invasion & & & & 0.023 \\
\hline No & 25 & 10 & 15 & \\
\hline Yes & 23 & 17 & 6 & \\
\hline Pathological differentiation & & & & 0.771 \\
\hline Moderate-high & 28 & 15 & 13 & \\
\hline Poor & 20 & 12 & 8 & \\
\hline Lymph node metastasis & & & & 0.019 \\
\hline Negative & 24 & 9 & 15 & \\
\hline Positive & 24 & 18 & 6 & \\
\hline TNM stage & & & & 0.040 \\
\hline I-II & 21 & 8 & 13 & \\
\hline III-IV & 27 & 19 & 8 & \\
\hline
\end{tabular}

TMN, tumour node and metastasis.

(targetscan.org), PicTar (pictar.mdc-berlin.de) and miRanda (www.microrna.org/microrna/home.do).

Western blot analysis. Total protein was isolated using radioimmunoprecipitation assay buffer (Beyotime Institute of Biotechnology, Haimen, China). A BCA assay (Nanjing KeyGen Biotech Co., Ltd., Nanjing, China) was used to measure total protein concentration. Equal amounts of protein $(20 \mu \mathrm{g} /$ lane $)$ were separated via SDS-PAGE on $10 \%$ gels, transferred onto polyvinylidene difluoride membranes (EMD Millipore, Billerica, MA, USA) and then blocked in 5\% non-fat milk for $1 \mathrm{~h}$ at room temperature. The membranes were incubated with mouse anti-human monoclonal PDCD4 antibody (1:1,000; cat. no. sc-376430; Santa Cruz Biotechnology, Inc., Dallas, TX, USA) and mouse anti-human monoclonal GADPH antibody (1:1,000; cat. no. sc-166574; Santa Cruz Biotechnology, Inc.), at $4^{\circ} \mathrm{C}$ overnight. Following washing, the membranes were incubated with goat anti-mouse horseradish peroxidase (HRP)-conjugated secondary antibody (cat. no. sc-2005; 1:2,000; Santa Cruz Biotechnology, Inc.) at room temperature for $2 \mathrm{~h}$. Protein bands were visualised using the
EMD Millipore Immobilon ${ }^{\mathrm{TM}}$ Western Chemiluminescent HRP Substrate (EMD Millipore).

Luciferase reporter assay. HEK293T cells were seeded into 24-well plates and co-transfected with pmirGLO-PDCD4-3'UTR wild type (Wt) or pmirGLO-PDCD4-3'UTR mutant (Mut) (both Chang Jing Bio-Tech, Ltd., Changsha, China), and an miR-503 or NC inhibitor, using Lipofectamine 2000 (Invitrogen; Thermo Fisher Scientific, Inc.), according to the manufacturer's protocol. Cells were harvested $48 \mathrm{~h}$ post-transfection. Luciferase activity was determined using Dual-Luciferase ${ }^{\circledR}$ Reporter Assay system (Promega Corporation) according to the manufacturer's protocol. Firefly luciferase activity was normalised to the Renilla luciferase activity.

Statistical analysis. Data were expressed as the mean \pm standard deviation and analysed using SPSS (version 15.0; SPSS Inc., Chicago, IL, USA). Statistical comparisons between groups were analysed using Student's t-test or one-way analysis of variance (ANOVA) plus multiple comparisons. Student-Newman-Keuls test was used as a post hoc test following the ANOVA. Spearman's rank correlation coefficient analysis was used to investigate the association between miR-503 and PCDC4 in LSCC tissues. P<0.05 was considered to indicate a statistically significance difference.

\section{Results}

miR-503 is upregulated in LSCC tissues and cell lines. miR-503 expression was measured in LSCC and the adjacent normal tissues by RT-qPCR. The results demonstrated that miR-503 was significantly upregulated in the LSCC tissues compared with the adjacent normal tissues $(\mathrm{P}<0.05$; Fig. 1A). The expression level of miR-503 in the LSCC cell lines was significantly increased compared with the HaCaT cell line $(\mathrm{P}<0.05$; Fig. 1B). These results suggested that miR-503 serves an important role in LSCC carcinogenesis and progression.

Association between miR-503 expression and LSCC clinicopathological features. The association between miR-503 expression and the clinicopathological features of LSCC patients was investigated. As illustrated in Table I, miR-503 expression level in LSCC demonstrated a significant association with thyroid cartilage invasion $(\mathrm{P}=0.023)$, lymph node metastasis $(\mathrm{P}=0.019)$ and tumour, node and metastasis (TNM) stage $(\mathrm{P}=0.040)$. However, no significant association was identified between the expression of miR-503 and other clinical features including age $(\mathrm{P}=0.776)$, sex $(\mathrm{P}=0.560)$, primary location $(\mathrm{P}=0.383)$ and pathological differentiation $(\mathrm{P}=0.771)$.

miR-503 regulates cellular proliferation and invasion of LSCC in vitro. To evaluate the roles of miR-503 in LSCC, its expression was silenced in AMC-HN-8 cells. AMC-HN-8 cells were transfected with a miR-503 inhibitor or a NC inhibitor. As illustrated in Fig. 2A, there was decreased expression of miR-503 in the miR-503 inhibitor-transfected AMC-HN-8 cells $(\mathrm{P}<0.05)$. The results of the CCK8 assay indicated that down-regulation of miR-503 inhibited the proliferation of AMC-HN-8 cells at $72 \mathrm{~h}(\mathrm{P}<005$; Fig. 2B). In addition, significantly fewer invasive 

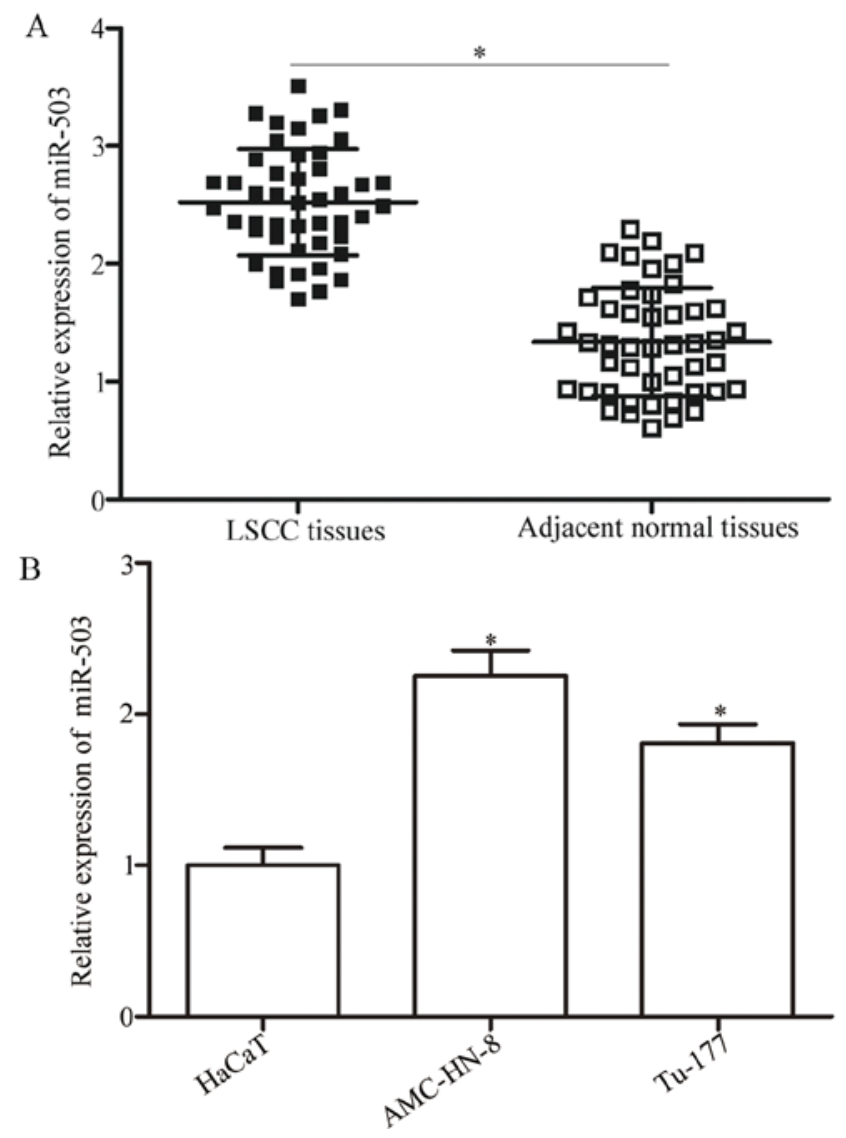

Figure 1. Analysis of the expression levels of miR-503 in LSCC tissues and cell lines. (A) The relative expression levels of miR-503 in LSCC tissues and adjacent normal tissues measured using the reverse transcription-quantitative polymerase chain reaction. (B) miR-503 expression in $\mathrm{HaCaT}$, AMC-HN-8 and Tu-177 cell lines. " $\mathrm{P}<0.05$ vs. the respective control. LSCC, laryngeal squamous cell carcinoma; miR, microRNA.

cells were observed in the AMC-HN-8 cells transfected with the miR-503 inhibitor ( $\mathrm{P}<005$; Fig. 2C). Therefore, miR-503 acts as an oncogene in LSCC.

PDCD4 is a direct target of miR-503. The function of miRs in human cancer is dependent on their target genes, so it is important to identify the targets of miR-503. Bioinformatic analysis was used to analyse the potential targets. As illustrated in Fig. 3A, a highly-conserved miR-503 targeting sequence was predicted in the 3'UTR of PDCD4, which indicates that PDCD4 is a potential target of miR-503. To confirm this hypothesis, a luciferase reporter assay was performed in HEK293T cells transfected with pmirGLO-PDCD4-3'UTR Wt or pmirGLO-PDCD4-3'UTR Mut, along with a miR-503 or NC inhibitor. The results indicated that a significant upregulation of luciferase activity was observed in the presence of the miR-503 inhibitor in the HEK293T cells co-transfected with the pmirGLO-PDCD4-3'UTR Wt $(\mathrm{P}<0.05)$, but not with the pmirGLO-PDCD4-3'UTR Mut (Fig. 3B). RT-qPCR and western blotting were then performed to detect PDCD4 expression in AMC-HN-8 cells transfected with miR-503 or $\mathrm{NC}$ inhibitor. As demonstrated in Fig. $3 \mathrm{C}$ and $\mathrm{D}$, down-regulation of miR-503 increased PDCD4 expression at the mRNA $(\mathrm{P}<0.05)$ and protein level in AMC-HN-8 cells. These results suggested that miR-503 negatively regulates
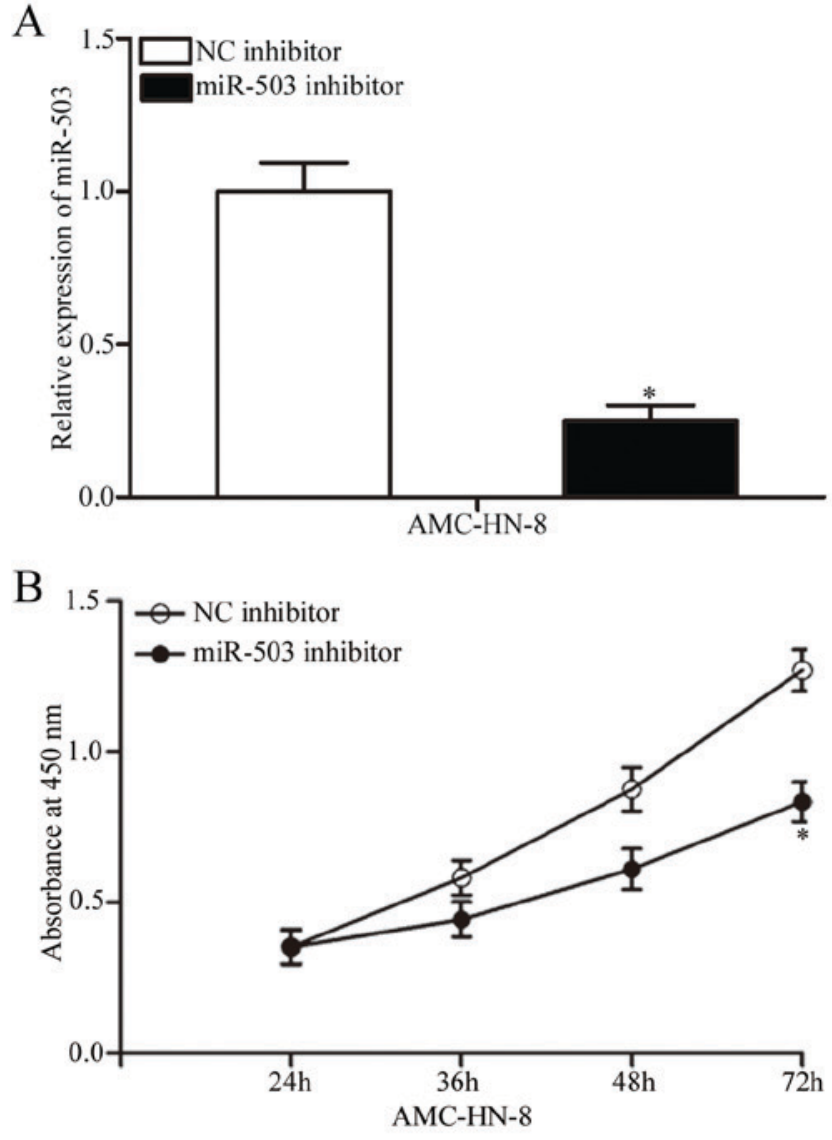

$\mathrm{C}$

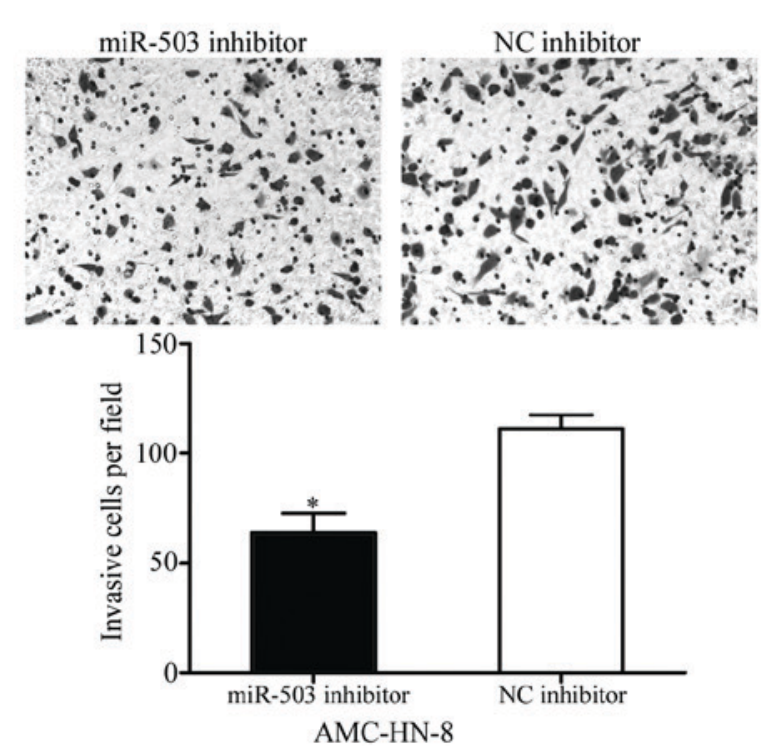

Figure 2. Investigation of miR-503 inhibition in AMC-HN-8 cells (A) Relative expression of miR-503 in AMC-HN-8 cells transfected with a miR-503 or NC inhibitor. (B) Absorbance at $450 \mathrm{~nm}$ of AMC-HN-8 cells transfected with a miR-503 or NC inhibitor. (C) Cell invasive ability of AMC-HN-8 cells transfected with a miR-503 or NC inhibitor was evaluated using a Transwell invasion assay (magnification, $\mathrm{x} 200$ ). ${ }^{*} \mathrm{P}<0.05$ vs. the respective control. miR, microRNA; NC, negative control.

PDCD4 expression through directly binding to the 3'UTR of PDCD4 gene.

PDCD4 overexpression exhibits similar effects to that of miR-503 underexpression in LSCC cells. The above results indicated that miR-503 negatively regulated PDCD4 expression and 
A

$\begin{array}{llll}\text { PDCD4-3' UTR Wt } & 5 \text {, ..AGGgGGAAAGUUAAGCUGCUAA... } \\ \text { hsa-miR-503 } & \text { 3' GACGUCUUGACAAGGGCGACGAU }\end{array}$

PDCD4-3' UTR Mut 5' ...AGGGGGAAAGUUAACGACGAAA... 3'
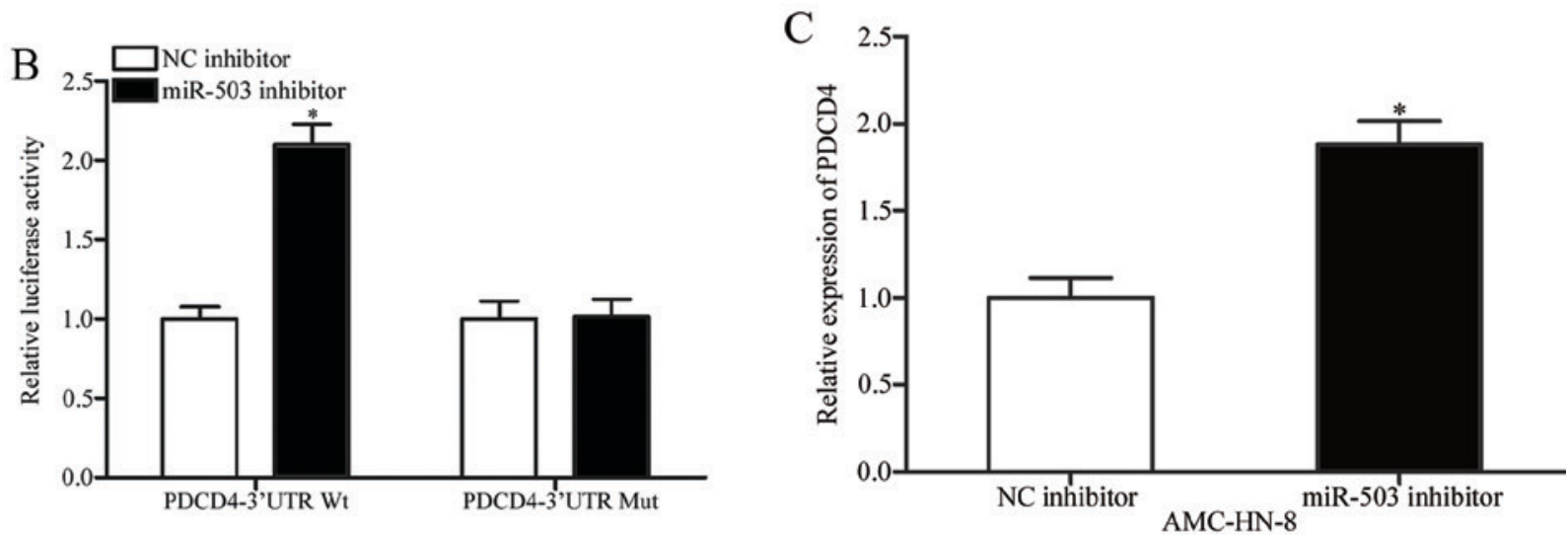

$\mathrm{D}$

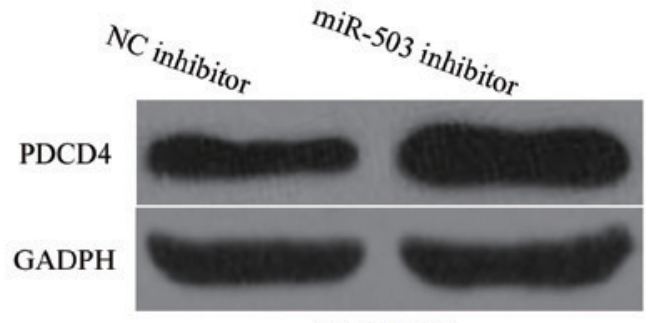

AMC-HN-8

Figure 3. Investigation of the interaction between PDCD4 and miR-503. (A) The putative miR-503-binding sites in the 3'UTR of PDCD4 and the corresponding mutant binding sites. (B) The relative luciferase activity of luciferase reporter vectors containing Wt or Mut PDCD4-3'UTR in HEK293T cells, which were co-transfected with the miR-503 inhibitor or NC inhibitor. (C) The mRNA levels of PDCD4 in AMC-HN-8 cells transfected with miR-503 inhibitor or NC inhibitor. (D) The protein levels of PDCD4 determined by western blot analysis in AMC-HN-8 cells transfected with miR-503 inhibitor or NC inhibitor. " $\mathrm{P}<0.05$ vs. the respective control. miR, microRNA; NC, negative control; PDCD4, programmed cell death protein 4; UTR, untranslated region; hsa, homo sapiens; Mut, mutant; Wt, wild type.

was involved in LSCC progression. Therefore, it was hypothesised that the effects of the down-regulation of miR-503 on AMC-HN-8 cells would be exhibited by PDCD4 re-expression. To confirm this hypothesis, pcDNA3.1-PDCD4 was transfected into AMC-HN-8 cells to increase PDCD4 protein expression (Fig. 4A). The CCK8 and transwell invasion assays demonstrated that increasing expression of PDCD4 inhibited the proliferation at $72 \mathrm{~h}(\mathrm{P}<0.05$; Fig. 4B) and invasion $(\mathrm{P}<0.05$; Fig. $4 \mathrm{C})$ of AMC-HN-8 cells. These results further demonstrated that PDCD4 is a direct functional target of miR-503 in LSCC.

PDCD4 is downregulated in LSCC tissues and is inversely correlated with miR-503 expression. PDCD4 mRNA in LSCC and adjacent normal tissues was detected using RT-qPCR. The results demonstrated that PDCD4 mRNA in LSCC tissues was significantly down-regulated compared with the adjacent normal tissues (Fig. 5A; $\mathrm{P}<0.05$ ). Spearman's rank correlation coefficient analysis illustrated that that the expression level of PDCD4 was inversely correlated with miR-503 expression in LSCC tissues $(r=-0.6021$; $\mathrm{P}<0.001$; Fig. 5B). Therefore, low PDCD4 mRNA expression in LSCC tissues was correlated with increased miR-503 expression.

\section{Discussion}

In the past two decades, a number of miRNAs were demonstrated to serve important roles in cellular processes, including proliferation, differentiation, metastasis, tumourigenesis and morphogenesis $(7,22)$. In the present study, miR-503 was observed to be upregulated in LSCC tissues and cell lines. miR-503 expression level in LSCC was correlated with thyroid cartilage invasion, lymph node metastasis and TNM stage. Transfection of LSCC cells with miR-503 inhibitor was demonstrated to inhibit cell proliferation and invasion by CCK8 and transwell invasion assay. Notably, PDCD4 was identified as a direct target gene of miR-503 in LSCC. These results demonstrated the expression level and roles of miR-503 in LSCC progression and suggested that miR-503 may serve as a prognostic and therapeutic target for LSCC.

A large number of studies have indicated that miR-503 was abnormally expressed in a number of types of human cancer. For example, in hepatocellular carcinoma, miR-503 expression was reduced in the primary tumour tissues and cell lines (23). In endometrioid endometrial cancer, the expression level of miR-503 was decreased and correlated with survival time of patients (24). In non-small cell lung 
A

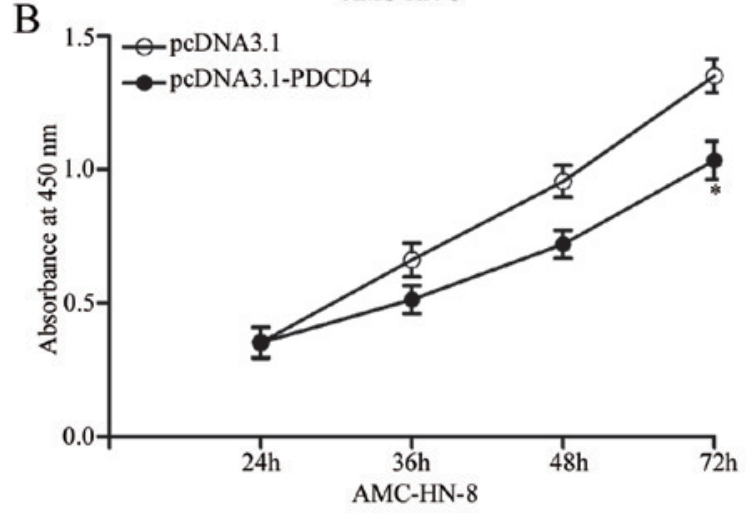

$\mathrm{C}$



Figure 4. PDCD4 overexpression inhibits cell proliferation and invasion in laryngeal squamous cell carcinoma. (A) Western blot analysis was performed to measure PDCD4 protein expression in AMC-HN-8 cells transfected with pcDNA3.1-PDCD4 or pcDNA3.1. (B) Absorbance at $450 \mathrm{~nm}$ of AMC-HN-8 cells transfected with pcDNA3.1-PDCD4 or pcDNA3.1 (C) Transwell invasion assay to evaluate the invasion ability of AMC-HN-8 cells transfected with pcDNA3.1-PDCD4 or pcDNA3.1 (magnification, $\mathrm{x} 200$ ). ${ }^{\text {"P }}<0.05$ vs. the respective control. miR, microRNA; PDCD4, programmed cell death protein 4.

cancer (NSCLC), miR-503 expression was down-regulated in tumour tissues and correlated with lymphatic invasion, distant metastasis, TNM stage, and tumour grade. In addition, Kaplan-Meier analysis revealed that patients with NSCLC with decreased expression of miR-503 exhibited a poor prognosis compared with patients with increased miR-503 expression. Additionally, multivariate analysis indicated that miR-503 expression in NSCLC was an independent prognostic factor for overall survival (25). miR-503 was also demonstrated to be down-regulated in glioma $(26,27)$, gastric cancer (28), osteosarcoma (17) breast (18), prostate (19) and cervical cancer (20). However, in oesophageal (29) and colorectal cancer (30), expression levels of miR-503 were increased in tumour tissues and associated with a poor
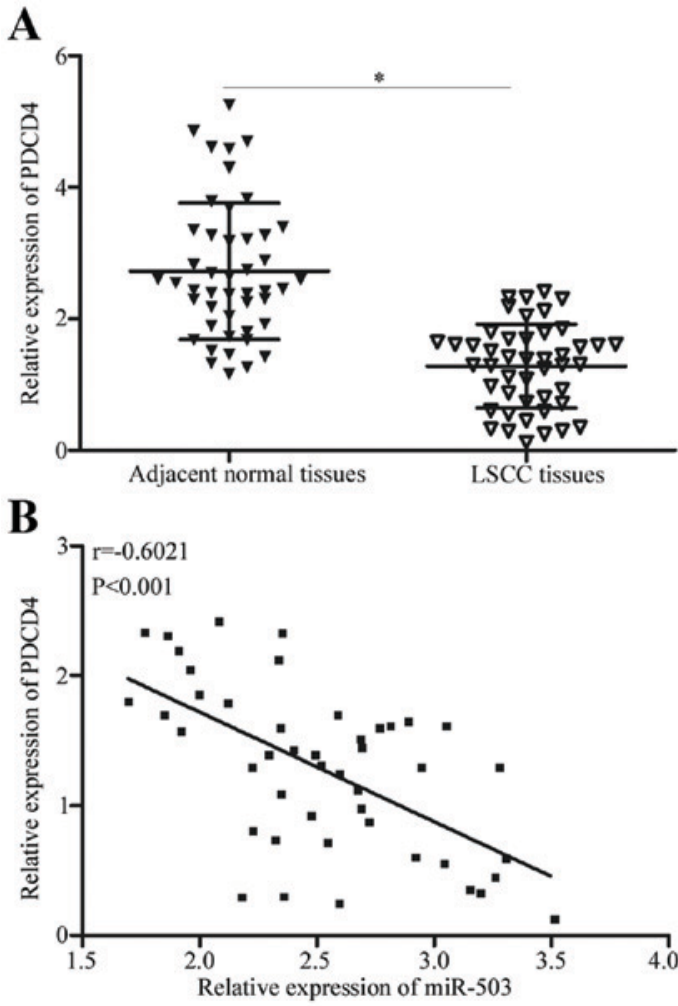

Figure 5. PDCD4 association with miR-503 expression in LSCC tissues (A) The relative expression of PDCD4 mRNA in LSCC tissues and adjacent normal tissues was measured using reverse transcription-quantitative polymerase chain reaction. (B) The correlation between PDCD4 mRNA and miR-503 expression level was analysed in LSCC tissues by Spearman's rank correlation coefficient analysis. ${ }^{*} \mathrm{P}<0.05$ vs. the respective control. LSCC, laryngeal squamous cell carcinoma; miR, microRNA; PDCD4, programmed cell death protein 4 .

prognosis. These results suggested that the dysregulation of miR-503 was a frequent event in numerous types of human cancer and may be a prognostic marker.

miR-503 has been demonstrated to be involved in various biological processes associated with tumourigenesis and tumour development. Zhou et al (23) reported that, in hepatocellular carcinoma, miR-503 re-expression inhibited tumour angiogenesis in vitro as well as in vivo via direct targeting of fibroblast growth factor 2 and vascular endothelial growth factor A. Xiao et al (31) revealed that miR-503 overexpression reduced cell growth through directly targeting insulin-like growth factor 1 receptor (IGF-1R). Xu et al (24) demonstrated that the restoration of expression of miR-503 targeted G1/S-specific cyclin-D1 to decrease cell viability, colony formation efficiency, cell-cycle progression in vitro and cell-derived xenograft viability in vivo. Yang et al (32) demonstrated that enforced miR-503 expression inhibited cell proliferation and metastasis of NSCLC in vitro and in vivo via inhibition of phosphoinositol 3-kinase (PI3K), PI3K regulatory subunit $\alpha$ and inhibitor of nuclear factor $\mathrm{\kappa}-\mathrm{B}$ kinase subunit $\beta$. Zhang et al (27) illustrated that abnormal expression of miR-503 attenuated cell proliferation by inducing G0/G1 cell cycle arrest and apoptosis, and decreased cell migration, and invasion through negative regulation of IGF-1R. In oesophageal carcinoma, down-regulation of miR-503 suppressed the proliferation and invasion of tumour 
cells by negative regulation of interleukin- 2 and interferon- $\gamma$ expression (33). These results suggested that miR-503 has a potential application in the treatment of a number of types of human cancer.

Identification of the miR target genes is important for understanding the role of miR in carcinogenesis. In the present study, an important molecular link between miR-503 and PDCD4 was observed in LSCC. Bioinformatic analysis predicted that PDCD4 is a potential target of miR-503. A luciferase reporter assay demonstrated that the 3'UTR of PDCD4 could be directly targeted by miR-503. RT-qPCR and western blot analysis indicated the regulatory effects of miR-503 on PDCD4 expression in LSCC. PDCD4 overexpression exhibits similar effects to that of miR-503 down-regulation in LSCC cells. PDCD4 is down-regulated in LSCC tissues and is inversely correlated with miR-503 expression level in LSCC tissues.

PDCD4 inhibits protein translation through binding to the translation eukaryotic initiation factor 4A-III, or via translation elongation by direct or indirect binding to the coding region of specific RNAs (34). Previous studies in tumour biology have demonstrated that PDCD4 expression was reduced in multiple types of human cancer, including hepatocellular carcinoma (35), gastric (36) and breast cancer (37). PDCD4 serves a pivotal role in the occurrence and development of LSCC. Wang et al (38) reported that PDCD4 expression was reduced in LSCC tissues compared with the normal laryngeal mucosa tissues. In addition, low PDCD4 expression was associated with different grading and lymphatic metastasis of patients with LSCC. In addition, PDCD4 expression was correlated with proliferation and apoptosis of LSCC cells (39). Li et al (40) also demonstrated that PDCD4 overexpression reduced the capacity of cellular metastasis in LSCC. These results suggested that targeting the miR-503/PDCD4 signaling pathway in LSCC may be promising in improving the efficacy of treatment and the clinical outcome.

In conclusion, the present study highlighted the regulatory mechanism by which miR-503-induced-loss of PDCD4 enhanced the proliferation and invasion of LSCC cells, and indicated that miR-503 could be investigated as a therapeutic target for the treatments of patients with this disease.

\section{References}

1. Ahmad Kiadaliri A, Jarl J, Gavriilidis G and Gerdtham UG: Alcohol drinking cessation and the risk of laryngeal and pharyngeal cancers: A systematic review and meta-analysis. PLoS One 8: e58158, 2013.

2. Ferlay J, Shin HR, Bray F, Forman D, Mathers C and Parkin DM: Estimates of worldwide burden of cancer in: GLOBOCAN 2008 Int J Cancer 127: 2893-2917, 2010.

3. Cai K, Wang Y and Bao X: MiR-106b promotes cell proliferation via targeting RB in laryngeal carcinoma. J Exp Clin Cancer Res 30: 73, 2011 .

4. Ji W, Guan C and Pan Z: Analysis of curative effects on laryngeal carcinoma patients in the northeast region of China. Acta Otolaryngol 128: 574-577, 2008.

5. Zhang K: Relation between air pollution and laryngeal cancer in Liaoning. Zhonghua Er Bi Yan Hou Ke Za Zhi 25: 240-242, 1990 (In Chinese)

6. Chu EA and Kim YJ: Laryngeal cancer: Diagnosis and preoperative work-up. Otolaryngol Clin North Am 41: 673-695, v, 2008.

7. Bartel DP: MicroRNAs: Genomics, biogenesis, mechanism, and function. Cell 116: 281-297, 2004.
8. Borel C, Deutsch S, Letourneau A, Migliavacca E, Montgomery SB, Dimas AS, Vejnar CE, Attar H, Gagnebin M, Gehrig C, et al: Identification of cis- and trans-regulatory variation modulating microRNA expression levels in human fibroblasts. Genome Res 21: 68-73, 2011.

9. Esteller M: Non-coding RNAs in human disease. Nat Rev Genet 12: 861-874, 2011.

10. Mendell JT: MicroRNAs: Critical regulators of development, cellular physiology and malignancy. Cell Cycle 4: 1179-1184, 2005.

11. Zhao Y and Srivastava D: A developmental view of microRNA function. Trends Biochem Sci 32: 189-197, 2007.

12. Bandrés E, Cubedo E, Agirre X, Malumbres R, Zárate R, Ramirez N, Abajo A, Navarro A, Moreno I, Monzó M and García-Foncillas J: Identification by real-time PCR of 13 mature microRNAs differentially expressed in colorectal cancer and non-tumoral tissues. Mol Cancer 5: 29, 2006.

13. Wu D, Zhou Y, Pan H, Zhou J, Fan Y and Qu P: microRNA-99a inhibiting cell proliferation, migration and invasion by targeting fibroblast growth factor receptor 3 in bladder cancer. Oncol Lett 7: 1219-1224, 2014.

14. Liang C, Zhang X, Wang HM, Liu XM, Zhang XJ, Zheng B, Qian GR and Ma ZL: MicroRNA-18a-5p functions as an oncogene by directly targeting IRF2 in lung cancer. Cell Death Dis 8: e2764, 2017.

15. Liu JY, Lu JB and Xu Y: MicroRNA-153 inhibits the proliferation and invasion of human laryngeal squamous cell carcinoma by targeting KLF5. Exp Ther Med 11: 2503-2508, 2016.

16. Geng J, Liu Y, Jin Y, Tai J, Zhang J, Xiao X, Chu P, Yu Y, Wang SC, Lu J, et al: MicroRNA-365a-3p promotes tumor growth and metastasis in laryngeal squamous cell carcinoma. Oncol Rep 35: 2017-2026, 2016.

17. Chong Y, Zhang J, Guo X, Li G, Zhang S, Li C, Jiao Z and Shao M: MicroRNA-503 acts as a tumor suppressor in osteosarcoma by targeting L1CAM. PLoS One 9: e114585, 2014.

18. Long J, Ou C, Xia H, Zhu Y and Liu D: MiR-503 inhibited cell proliferation of human breast cancer cells by suppressing CCND1 expression. Tumour Biol 36: 8697-8702, 2015.

19. Guo J, Liu X and Wang M: miR-503 suppresses tumor cell proliferation and metastasis by directly targeting RNF31 in prostate cancer. Biochem Biophys Res Commun 464: 1302-1308, 2015.

20. Yin ZL, Wang YL, Ge SF, Guo TT, Wang L, Zheng XM and Liu J: Reduced expression of miR-503 is associated with poor prognosis in cervical cancer. Eur Rev Med Pharmacol Sci 19: 4081-4085, 2015

21. Livak KJ and Schmittgen TD: Analysis of relative gene expression data using real-time quantitative PCR and the 2(-Delta Delta C(T)) method. Methods 25: 402-408, 2001.

22. Lagos-Quintana M, Rauhut R, Lendeckel W and Tuschl T: Identification of novel genes coding for small expressed RNAs. Science 294: 853-858, 2001.

23. Zhou B, Ma R, Si W,Li S, Xu Y, Tu X and Wang Q: MicroRNA-503 targets FGF2 and VEGFA and inhibits tumor angiogenesis and growth. Cancer Lett 333: 159-169, 2013.

24. Xu YY, Wu HJ, Ma HD, Xu LP, Huo Y and Yin LR: MicroRNA-503 suppresses proliferation and cell-cycle progression of endometrioid endometrial cancer by negatively regulating cyclin D1. FEBS J 280: 3768-3779, 2013.

25. Liu L, Qu W and Zhong Z: Down-regulation of miR-503 expression predicate advanced mythological features and poor prognosis in patients with NSCLC. Int J Clin Exp Pathol 8: 5609-5613, 2015

26. Liu H, Song Z, Liao D, Zhang T, Liu F, Zheng W, Luo K and Yang L: miR-503 inhibits cell proliferation and invasion in glioma by targeting L1CAM. Int J Clin Exp Med 8: 18441-18447, 2015.

27. Zhang Y, Chen X, Lian H, Liu J, Zhou B, Han S, Peng B, Yin J, Liu W and He X: MicroRNA-503 acts as a tumor suppressor in glioblastoma for multiple antitumor effects by targeting IGF-1R. Oncol Rep 31: 1445-1452, 2014.

28. Peng Y, Liu YM, Li LC, Wang LL and Wu XL: microRNA-503 inhibits gastric cancer cell grow th and epithelial-to-mesenchymal transition. Oncol Lett 7: 1233-1238, 2014.

29. Ide S, Toiyama Y, Shimura T, Kawamura M, Yasuda H, Saigusa S, Ohi M, Tanaka K, Mohri Y and Kusunoki M: MicroRNA-503 promotes tumor progression and acts as a novel biomarker for prognosis in oesophageal cancer. Anticancer Res 35: 1447-1451, 2015.

30. Noguchi T, Toiyama Y, Kitajima T, Imaoka H, Hiro J, Saigusa S, Tanaka K, Inoue Y, Mohri Y, Toden S and Kusunoki M: miRNA-503 promotes tumor progression and is associated with early recurrence and poor prognosis in human colorectal cancer. Oncology 90: 221-231, 2016. 
31. Xiao Y, Tian Q, He J, Huang M, Yang C and Gong L: MiR-503 inhibits hepatocellular carcinoma cell growth via inhibition of insulin-like growth factor 1 receptor. Onco Targets Ther 9: 3535-3544, 2016.

32. Yang Y, Liu L, Zhang Y, Guan H, Wu J, Zhu X, Yuan J and Li M: MiR-503 targets PI3K p85 and IKK-beta and suppresses progression of non-small cell lung cancer. Int J Cancer 135: 1531-1542, 2014.

33. Zhao K, Chen BJ, Chen ZG, Zhang YJ, Xu D and Liu Q: Effect of miR-503 down-regulation on growth and invasion of esophagus carcinoma and related immune function. Med Sci Monit 21: 3564-3569, 2015

34. Wang L, Jiang Y, Song X, Guo C, Zhu F, Wang X, Wang Q, Shi Y, Wang J, Gao F, et al: Pdcd4 deficiency enhances macrophage lipoautophagy and attenuates foam cell formation and atherosclerosis in mice. Cell Death Dis 7 : e2055, 2016.

35. Zhang H, Ozaki I, Mizuta T, Hamajima H, Yasutake $\mathrm{T}$, Eguchi Y, Ideguchi H, Yamamoto K and Matsuhashi S: Involvement of programmed cell death 4 in transforming growth factor-beta1-induced apoptosis in human hepatocellular carcinoma. Oncogene 25: 6101-6112, 2006.
36. Liang H, Wang F, Chu D, Zhang W, Liao Z, Fu Z, Yan X, Zhu H, Guo W, Zhang Y, et al: miR-93 functions as an oncomiR for the downregulation of PDCD4 in gastric carcinoma. Sci Rep 6: 23772, 2016.

37. Frankel LB, Christoffersen NR, Jacobsen A, Lindow M, Krogh A and Lund AH: Programmed cell death 4 (PDCD4) is an important functional target of the microRNA miR-21 in breast cancer cells. J Biol Chem 283: 1026-1033, 2008.

38. Wang J and Zhang Y: Expression of programmed cell death 4 protein is closely correlated with laryngeal squamous cell carcinomas. Lin Chung Er Bi Yan Hou Tou Jing Wai Ke Za Zhi 25: 539-541, 2011 (In Chinese).

39. Wang $\mathbf{J}$ and Zhang Y: Expression of programmed cell death 4 and its correlation with proliferation and apoptosis in laryngeal squamous cell carcinoma. Lin Chung Er Bi Yan Hou Tou Jing Wai Ke Za Zhi 26: 266-269, 2012 (In Chinese).

40. Li JZ, Gao W, Lei WB, Zhao J, Chan JY, Wei WI, Ho WK and Wong TS: MicroRNA 744-3p promotes MMP-9-mediated metastasis by simultaneously suppressing PDCD4 and PTEN in laryngeal squamous cell carcinoma. Oncotarget 7: 58218-58233, 2016. 